\title{
NEW DIRECTIONS IN DEVELOPMENT - CASES OF HIGH, MEDIUM AND LOW TECHNOLOGIES
}

\author{
Daryl Hobbs*
}

The South has lagged behind only the West among the four regions of the nation in relative growth of population and employment during the past two decades. This has occurred largely because both jobs and people have moved to the region from other regions. To an important extent, the South has gained from what the North and East lost.

One reasonable approach to designing future economic development strategies for the region is to assess the prospects for continuation of forces that have contributed most to past growth. But that necessitates questioning whether Southern growth of the recent past was attributable to unique historical circumstances affecting the region and therefore unlikely to continue, or whether it is reasonable to expect a continuation of past trends.

This paper emphasizes that the South will probably continue to enjoy a comparative advantage regarding those factors that have contributed most to past growth. But we will also emphasize that some of the factors contributing to Southern regional growth in the 1960s and 70s will not likely be sustained to the same degree in the 1980s and 90s-anywhere in the nation. Thus, even though the South may retain a comparative advantage with regard to some growth factors, those factors will not likely translate into a continuation of the same rate of associated population and job growth. Because of a probable slow down, we will engage in some speculation about some potential new sources of Southern regional growth.

This paper devotes most of its attention to social and demographic influences that have contributed to past economic change and growth. Similarly in speculating about new directions most of the emphasis will be on social and demographic factors.

\section{Growth Factors in the 60s and $70 \mathrm{~s}$}

The period from 1900-1970 was one of rapid national industrialization; agriculture and rural areas were not exempt from the influences. One of the most obvious consequences was a massive outmigration from rural areas (especially in the South and Midwest) to the industrial centers, predominantly in the North and East.

The impact was so pervasive that a Presidential Commission on Rural Poverty, working in the mid1960 s, entitled its report "The People Left Behind"-those rural people, typically the young, with skills and resources having departed for urban labor markets, leaving behind many rural poor, especially the elderly and those lacking marketable skills. The South was largely the focus of the People Left Behind.

However, the ink was scarcely dry on the People Left Behind when it became apparent that the previously uninterrupted trends had begun to change. Especially in the South and West, not only were metropolitan areas growing, but in many parts of those regions the small town and rural population had begun to increase as well. To some extent this growth came at the expense of the Northeast where employment and population in the larger cities began to decline. Older, labor intensive industries often led the move as they found lower wage rates in Southern, often rural, areas. Concomitantly, in many parts of the country, but especially in the South, the number of places the census classifies as farms

*Professor of Rural Sociology, University of Missouri-Columbia. 
actually began to show slight increases. But these increases were not occurring uniformly across the country. Increases were being recorded most often in areas of relatively low agricultural productivity (and thus low land values) and where rural and small city manufacturing employment was increasing. Those circumstances contributed to the emergence of a new class of farms, farms on which operators became more dependent on off-farm income than farm income. The new factory jobs and retirement income, factors to be discussed at greater length, contributed to many previously "marginal" farms becoming "part-time" farms.

The reason for the increase in population in the South, and in many rural communities in the South, during the 1970 s was simply that past trends "turned around"-more people moved in, or stayed put, than moved out. In addition to industrial re-location we will take a look at some other factors that contributed to this inter- and intraregional redistribution.

As alluded to above, a distinctive feature of recent Southern economic and population growth has been that it occurred in both rural and metropolitan parts of the region. That is a departure from previous patterns of industrialization when employment and population growth were generally confined to cities. Because that is an unusual feature of the recent Southern experience (shared to an extent nationally), we will direct special attention to rural growth.

\section{Employment}

Throughout the 1960s and 70s there was a larger increase in employment in the South and West than in the North and East.

One concomitant factor was an increase in employment in non-metropolitan areas, especially in the South. The late 1960 s and the 1970 s was a period of industrial growth in rural areas throughout the country-largely attributable to re-location of mature industries. For the nation as a whole, there was a 12 percent increase in metropolitan employment from 1970 to 1977 while a 27 percent increase in non-metropolitan employment occurred. But the South did better than that. Throughout the Southern region, for example, there was a 23 percent increase in metropolitan wage and salary employment during that period but a 30 percent increase in corresponding non-metropolitan employment. Consequently, a major contributor to Southern and rural population increase during the 1970s was that many Southerners no longer found it necessary to move to industry and employment-to an important degree, industry and employment had moved to them.

While lower regional and rural wage rates provided an inducement for industrial re-location, competition among states and communities for new industry also contributed. This competition led to initiatives and concessions. Certainly in the South a regional strategy in the form of public investments in vocational schools, industrial parks, tax concessions, etc., added to the attractiveness of the region. Many rural communities, having suffered declines in agriculture, devoted great effort to attracting industry to their town.

Yet another form of public investment which undoubtedly contributed to Southern and rural growth was construction and improvement of roads and highways. Although it is difficult to be precise, it is probable that the Interstate highway system had a strong influence on the rural and regional industrial and population redistribution. Because of the Interstate system, and other major road improvements, the South became more accessible. The question of accessibility had been regarded as so important that highway construction was one of the principal initiatives of the Appalachian Regional Commission.

Because of the Interstate system, it became more economically feasible (for transportation of both industrial inputs and outputs) for production facilities to be located on the basis of other attractions including wage rates and other public initiatives where the South had, or produced, a comparative advantage.

\section{Retirement}

Another important contributor to the growth of the Southern and rural economy and population has been the nationwide growth in the cohort of retired people and the resources they have to retire on. A number of factors have combined to make retired people and their sources of income more demographically and economically significant. Through expanded benefits of both public and private retirement programs, a cohort of 12 percent of the nation's population but about 30 percent of the households are 
now receiving some form of retirement income (US Statistical Abstract). As a result, many of these families have been enabled to become more geographically mobile.

The South, and rural areas of the South, have gained retired people disproportionately to the rest of the country over the past two decades. Their presence has added substantially to the economic base of many parts of the South because retired people typically bring their income with them. The impact is observed broadly across the region and is not confined to some of the highly visible retirement communities in Florida. In addition to better climate there have been other attractions of the South and especially many of its rural areas:

1. Regional and rural-urban differentials in property values and cost of living

A factor influencing the shift of retired population toward the South and rural areas has been differentials in property values between metropolitan and rural areas and between regions. A person who bought a house in a metropolitan area during the 1950 s would have realized significant appreciation in its value by the late 1970s. Persons in that situation, planning to retire in the 1970 s, could have sold their property in a metropolitan area, moved to a rural area and purchased a home and/or some land and, in many cases, realized significant cash equity in the process. Consequently, for many, a move to a rural area, or a lower cost of living region, often provided a way of realizing a significant gain in their retirement resources. Thus, it appears that for many people facing retirement in the 1970 s there was a strong economic incentive to move from a higher to a lower cost of living region or community. Many parts of the South and especially rural areas offered this opportunity. The opportunity to also supplement income by retiring on an inexpensive small farm became a popular option.

\section{Residential Preferences}

For the past two decades, major public opinion polling organizations have asked the public from time to time where they would prefer to live if given a choice. These polls have usually found that a majority, whether urban or rural residents, would prefer to live in a rural area or small town or city (Zuiches, 1982). Despite this preference, the net flow of population movement in the country until the late 1960s was from rural areas to metropolitan areas largely because that's where the jobs were. Residential preferences were a secondary consideration.

We might reason, however, that if it became economically possible for more people to exercise their residential preference and still make a living, that more people might do so. That is basically what happened in the 1960s and 1970s. Industrial re-location and expanded retirement benefits enabled many to become geographically mobile.

3. Early retirement and second "careers"

Recently, people joining the ranks of the retired have not always been elderly. Military personnel, civil service employees and many others have, in recent years, become eligible for retirement benefits after 30 years of service or even less. Consequently, it has become possible for many to retire on benefits at age 55 or even younger.

This growth of younger retirees coincides with large numbers who had been in military service during World War II. Many veterans either stayed on in the military, or entered various forms of government employment, following active service in World War II. Their years of service in the military counted for retirement purposes in the civil service. Consequently, people who entered the armed services between 1941 and 1945 could have put in 30 years of retirement eligible service between 1971 and 1975 . In 1960, for example, there were 250,000 military veterans receiving retirement pay; by 1980 this had increased to 1.5 million (US Stat. Abstract). This, however, only counts those who retired from the military-it does not include those who applied their years of military service to other forms of civil service employment.

"Early" retirees tend to add more than their presence and income to the areas they retire to. They tend to remain economically active. We have observed in the Missouri Ozarks that counties having the highest recent rates of in-migration of 55-64 year olds are also counties that have experienced the highest rates of formation of small businesses and have gained in numbers of small farms.

\section{Public Amenities}

In addition to climate and lower cost of living, the combination of industrial re-location, public investments, and improved roads and highways all contributed to an enhancement of other public amenities and services. Moving to a rural area of the South no longer necessarily meant being deprived of access 
to health care, retail services, etc. It is fair to assume that one form of growth produced features that stimulated other forms of growth and established a foundation for future economic development strategies as well.

We have concentrated attention on only two major growth factors-industrial re-location and retirement. Others such as growth in tourism, the travel industry, defense installations, etc. have also played an important role. However, before turning to discussion of prospects for continuation of these trends and some possible new directions of growth, we call attention to a couple of other regional dynamics that have played a facilitating role, especially in intraregional redistribution.

\section{Mobility}

If there are good roads and highways, it is then easier for people to live in small communities or rural areas and commute for work and services to larger towns and cities. Mobility of Americans shows little evidence of having been deterred by rising energy prices. Total passenger car miles driven increased by 25 percent from 1970 to 1980 .

Improved mobility has made it possible for more people to hold jobs in an urban center and still exercise their residential preference. As an indication of that effect, an important part of the "rural" population increase has occurred in rural counties surrounding larger metropolitan areas: in effect a part of the rural population turnaround has been metropolitan sprawl. Improved mobility has also undoubtedly contributed to some industries choosing rural plant locations-plant location not being as constrained by labor supply within the immediate community but rather being able to draw on that available within commuting range.

Intraregionally improved mobility seems associated with some decentralization of both employment and population. Economic and population growth has not been equally dispersed but neither has it been highly concentrated. All states in the region have experienced both metropolitan and non-metropolitan employment and population growth.

\section{Households and Housing}

A recent demographic trend having important economic implications has been a nationwide increase in the number of households in relation to increases in population. Put simply, there are fewer people per household today than ever before. Because the South has attracted large numbers of older migrants, the region has experienced a disproportionately large increase in number of households. In the midSouth region (Ky., Tenn., Ala., Miss.) the number of households increased by 31 percent between 1970 and 1980 while the total population increased by only 14 percent. In the Southeast (NC, SC, Ga., Fla.) the number of households increased by 47 percent while population increased by 27 percent from 1970 to 1980 (US Statistical Abstract).

The proportionally larger increase in households in relation to the population is attributable not only to demographic factors-aging of the population and the baby boom generation establishing households -but to social and economic factors as well. Since the late 1960s there has been a dramatic increase in the divorce rate (often resulting in replacing one household with two) and it has become socially acceptable and economically possible for more unmarried young adults to establish their own households. Projections of the future rate of household formation must take into account social and economic as well as demographic changes. For example, there was a decline in the number of households during the depression of the 1930s as nuclear families reformed extended families as an adaptation to economic conditions.

To an extent, growth in households contributes more to demand for certain goods and services than growth in the overall population. Especially affected is the demand for housing, and goods and services associated with household management and operation.

One response to the increased demand for housing that has been especially noticeable in the South was the increased use of manufactured housing. The South has recently led all regions by a wide margin in the placement of mobile homes for permanent residence. For the period from 1974 to 1980, half of all mobile homes placed for residence across the nation were located in the South. Between 1970 and 1980, mobile homes accounted for more than 20 percent of all new private housing in the South (US Statistical Abstract). Because of the lower cost of mobile homes in relation to conventional housing, and perhaps 
more importantly, because of their immediate availability, we see the mobile home as having facilitated some intraregional population redistribution. It is probable that a lack of affordable housing may have deterred some movement to the South, and from urban to rural areas within the region, had manufactured housing not been available as an alternative.

\section{Prospects for Continuation of Past Trends and Emergence of New Ones}

We stated at the outset that one approach to devising economic development strategies is to assess the prospects for continuation of past trends. The growth factors we have discussed offer, in our judgment, a mixed prospect for continuation.

\section{Industry and Employment}

The South has now clearly become established as a major industrial region in the country. The regional economy is broadly diversified with a share of technology based and major fabrication industry. But, as we have emphasized, much of the recent industrial growth, especially in rural areas, is attributable to immigration of labor intensive industry from other regions. However the prospect of that trend continuing, or for that matter the prospect of all the recently arrived industry remaining in the region, is more problematic. Such industries, having exhibited a propensity to move to lower wage rates and other inducements can be expected to find even lower wage rates elsewhere attractive. Several recent works (e.g. Bluestone and Harrison, 1982) have called attention to the loss of low wage labor intensive industry to other countries. Insofar as the U.S. loses such industries to other countries, the South is likely to be most affected because of the recent concentration there.

We have observed that the Interstate highway system and other public investment in regional infrastructure played a role in the recent economic growth of the South. A growth spurt was realized because the South became more accessible, thus making other features of the region more attractive. We can conclude that that impetus to growth has now been generally realized. However, an enduring effect is that the South is no longer at a locational disadvantage in relation to other regions and to the potential for future economic development.

Assuming a decline in employment in some industries, then what are the prospects for replacement? The South, having an attractive climate and having added greatly to its population and infrastructure, can be expected to be competitive with other regions in attracting and developing more technology and skill based enterprises. A key here seems to be continued improvement in the training and skills of the labor force. Investment in human capital would seem to have the highest probability for return. Given the recent history of job creation by small business, especially in the tertiary sector (e.g. The State of Small Business, 1984), a part of the future development strategy would probably devote more attention to entrepreneurship and job creation and some less effort to attracting existing mature industries from other locations.

Much is also being written these days about growth in high technology industries and employment. The promise of "high tech" has excited many concerned with economic development. It is probable however that high technology firms will not contribute greatly to future employment in any region of the country (Tomashovic-Devey and Miller, 1983). However, where high tech firms are appearing, their locational considerations may be instructive for devising future economic development strategies. (Graham, 1982.) We also have some evidence from a recent survey of high technology firms located in nonmetropolitan college and university towns across the country (Buck, Hobbs et al., 1984). We were seeking from these firms an indication of factors they took into account in locating where they did.

We received completed questionnaires from 300 high tech firms located in the 57 college/university communities we surveyed. One fourth of the communities and one fourth of the completed questionnaires were from the South-places like Clemson, Auburn, Athens, Ga., etc.

Pertinent to the survey was the premise that high technology firms (those with a relatively high ratio of scientific and technical to production personnel) would find college/university towns attractive because of the concentration of research, and research support, to be found there. Indeed we found 1500 "high tech" firms in the 57 communities we surveyed-that in itself providing some confirmation of our reasoning about human capital concentration.

The 300 responding firms were asked to indicate the degree of importance they attached to each of 57 different business location factors. Ranked on the basis of the proportion of respondents indicating 
each factor as being either "absolutely critical" or "very important" we found the top eight factors to be (in order): clean physical environment, availability of technical personnel, level of crime, drug/alcohol problems in the community, quality public schools, low traffic congestion, knowledgeable local bankers friendly to technology, policies/attitudes of local government toward industry, and one-day package service. Ranking far down the list of important considerations were such factors often associated with industrial development as average wage rates, freight services, industrial parks, sewer and water capacities, etc.

While this survey was done with an as-yet atypical set of firms in rather atypical communities the results may at least be suggestive of some future economic development directions. Availability of skilled personnel, quality of community life, and institutional support services may gain in future importance as determinants of geographic location for a broader spectrum of economic development.

Associated with discussions about "high tech" development is a more than corresponding growth in the tertiary sector-the so-called service based economy. Indeed the terms "high tech" and "high touch" are often used in tandem in describing recent changes.

Service based employment will surely grow in the South as in other regions. The South, having emerged as an economically diversified region, can reasonably expect further developments in regional and international trade, finance, transportation, etc. But such developments are likely to be concentrated in major metropolitan centers. Looking across the region, service based employment, especially that directed toward meeting human and household needs, is likely to grow in most parts of the region, but perhaps most greatly influenced by social and demographic factors and changes. For that reason we turn now to a concluding discussion about demographic and social trends likely to influence some tertiary sector expansion in employment.

2. Retirement, Working Women and Other Contributors to Service Sector Growth

We have called particular attention to retirement in the South because of both the direct economic impact and the concomitant growth of the tertiary sector.

Demographically it is certain that the proportion of older and retired persons in the population will increase. It is probable also for reasons of both climate and lower cost of living that the South will continue to attract retired immigrants. The South has also added to its attractiveness through enhanced amenities in recent years.

However, future planning with regard to this contributor to growth should be sensitive to some possibilities for change in rate and/or direction. It is probable that the rate of increase of this cohort will begin to stabilize in the South. Because of a combination of generally liberalized retirement benefits, the bulge of retirement eligible World War II veterans, the growth of the retirement age cohort and a general improvement in standard of living, the phenomenon of a sizable, geographically mobile cohort of retirees became much more visible in the late 1960s and early 70s. The South, as we have noted, offered many attractions and became a disproportionate recipient of retirees-rather generally across the region. The phenomenon of a geographically mobile retirement population is now here to stay, and it is unlikely that any future shifts will be as dramatic and noticeable as that which occurred $10-15$ years ago.

However there are predictable stages in the life cycle of retirees and some of these will become more apparent in the South. As younger retirees (55-65) become older they often find it necessary to once again become mobile, especially if they retired to a small farm, a rural area, or a second career enterprise. If there is a move, it is likely to be to a town or small city that has full health care and other needed services. Some redistribution of older retirees $(70+)$ can be expected in many parts of the South. That prospect gives rise to a related question - will the places (small farms, businesses, etc.) given up by older retirees, prove to be attractive to subsequent cohorts of retirees? If there is a succession, little economic change will be noted. If there isn't, many rural communities could stand to lose an important component of their economic base.

Associated generally with the retirement phenomenon is a set of questions concerning present and future prospects for growth in the tertiary sector. Increased numbers of retired persons translate into increased income in a locality and a corresponding increase in demand for goods and services. It is probable therefore that many rural communities could find some potential for job creation by responding to the need for services especially pertinent to retired persons and/or the elderly. Expanded services, 
where economically justified in some localities, could contribute to lowering the probability of some retired persons moving closer to services.

Of regional importance also is the fact that older persons generate a proportionally larger demand for health care-a sector that has grown dramatically to the point where it now accounts for more than 11 percent of GNP.

But a projected growth in demand for services (and the job creation potential that represents) is not limited to responding to a demand generated by retired persons. There are other socio-economic changes, such as the significant increase in the number of women in the labor force, which also translate into a demand for more services. As women leave a role as full-time homemaker, services such as child care, home maintenance, meals, etc. are more often purchased. Although there has been growth in such home related services there appears to be potential for further expansion. For example, according to recent estimates only about 20 percent of the care of preschool children of working mothers is being provided for by licensed day care centers.

The above are intended only as examples but they illustrate that social and demographic changes often contribute to economic changes as well.

\section{Conclusion}

The recent growth of the South has been spurred greatly by the re-location of industry and population from other regions. Associated with that growth has been a diversification of the economy of the region, an enhanced infrastructure and some relative economic and employment gain although the South still has a higher proportion of low income population than other regions.

We have suggested that past contributions to growth are unlikely to be sustained to the same extent. There is less likelihood today than 20 or 30 years ago of major interregional movements of mature industries. Indeed the South may lose some of the re-located industry to other nations.

The South has probably reached a stage in its regional development where major attention can best be directed toward strategies that are focused within the region-those that depend largely on resources that are either present or can be developed in the region. Therefore strategies having the greatest prospect for future growth would seem to be little different from those that apply to the nation as a whole. High on the list is likely to be further development of human capital and greater attention to job creation than to industrial attraction per se.

\section{REFERENCES}

Bluestone, Barry and Bennet Harrison. The Deindustrialization of America. New York: Basic Books, 1982.

Buck, A., Hobbs, D., et al. Feasibility of High Tech Companies Incubation in Rural University Settings. SBIR Report. Rolla, MO: INCUTECH. March, 1984.

Galambos, Eva C. Technician Manpower in the South: High Tech Industries or High Tech Occupations? Atlanta: Southern Regional Education Board. 1983.

Graham, S.G. The Determinants of the Geographical Distribution of the Formation of New and Small Technology-Based Firms. Washington, D.C.: US Dept. of Commerce. NTIS. June, 1982.

Tomashovic-Devey, Donald, and S.M. Miller. "Can High Tech Provide the Jobs? Challenge, 26:2, 57-63. May/June, 1983.

U.S. Bureau of the Census. Statistical Abstract of the U.S., 1982-83. Washington, D.C.: Superintendent of Documents. 1983.

U.S. Government. The State of Small Business: A Report of the President. Washington, D.C.: US Govt. Printing Office. March, 1984.

Zuiches, James: "Residential Preferences." Chapter 24 in Dillman, Don and Daryl Hobbs (eds.), Rural Society in the U.S., Boulder, CO: Westview Press. 1982. 